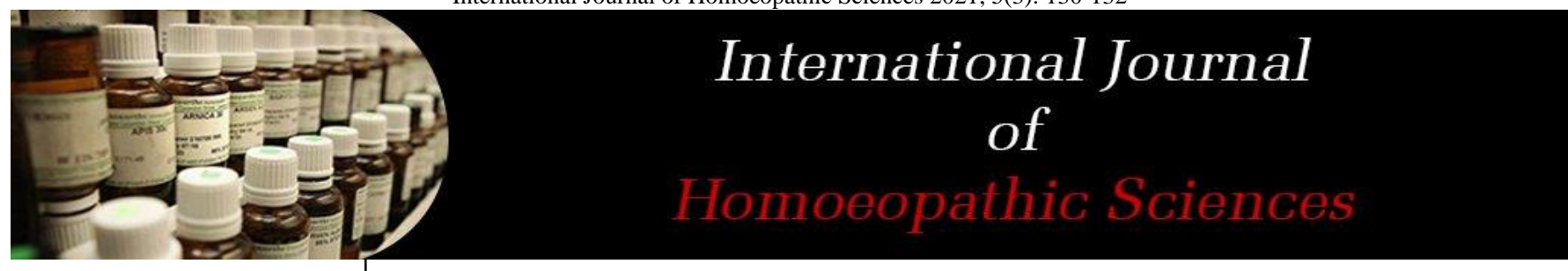

E-ISSN: $2616-4493$

P-ISSN: 2616-4485

www.homoeopathicjournal.com IJHS 2021; 5(3): 130-132

Received: 04-05-2021

Accepted: 06-06-2021

Dr. Shyambhavi Chaudhary Head of Department, Department of Physiology, Bakson Homoepathic Medical College \& Hospital, Greater

Noida, Uttar Pradesh, India

Dr. Varun Chaudhary Guest Faculty, Depart of Organon of Medicine, Bakson Homoepathic Medical College \& Hospital, Greater Noida, Uttar Pradesh, India
Corresponding Author: Dr. Varun Chaudhary Guest Faculty, Depart of Organon of Medicine, Bakson Homoepathic Medical College \& Hospital, Greater Noida, Uttar Pradesh, India

\section{0 millesimal prescribing in case of jagged warts: A case report}

\section{Dr. Shyambhavi Chaudhary and Dr. Varun Chaudhary}

DOI: https://doi.org/10.33545/26164485.2021.v5.i3c.415

\section{Abstract}

The 50 millesimal potency was given by Dr. Samuel Hahnemann, as described in footnote to aph.270, as a perfect way of potentisation, It is a powerful and mildest way of administration of medicine in the least material form but at the same time increased in power by each dynamization 50,000 times ${ }^{[1]}$.

Warts or Verruca are small, fleshy outgrowth on skin or mucus membrane caused by Human papilloma virus. There are a number of variants on the basis of their type, mode of entry and susceptibility of the host ${ }^{[2]}$

Keywords: 50 millesimal, potentisation, verruca, jagged

\section{Introduction}

A male patient, aged 38yrs, reported with the complaint of wart over right upper corner of lip and a cluster of identical warts over chin for 5-6 months.

Presenting complaint: The patient presented with wart over right corner of upper lip and a cluster of warts over chin, for 5-6months. Warts with sharp pointed, rough edges, dry in appearance with slight itching. Associated complaint was distension of stomach with bloated feeling and sour eructations, which is aggravated during travelling, for 2-3 years. Patient also had a history of recurrent apthae.

History of presenting complaint: Patient was apparently well $1 \frac{1 / 2}{2}$ year back when he suffered with similar kind of warts over chin and around neck, for which he took allopathic treatment and got cauterization done. Now for 5-6 months he again presented with similar warts over chin with a slight itchy sensation over it.

Family history: Significant history of mother having skin problem and skin tags over the body.

\section{Physical generals}

- Desire - spicy, rice

- Intolerance - spicy, fried

- Sweat - over nose and forehead

- Tongue - indented edges.

- Sleep - disturbed at night but very sleepy in morning

- Decubitus - comfortable to sleep on belly

- Thermal reaction: sensitive to cold, feel chilly.

\section{Mental generals}

- Arrogant, dominating in nature.

- Angers easily and doesn't wish to talk when angry.

- All of a sudden he forgets what he was thinking of.

\section{Analysis and Evaluation of symptoms}

- Arrogant and dominating in nature.

- Angers easily.

- Suddenly forgets what he was thinking of. 
- Desire for spicy, fried food.

- Sleepy in morning.

- Sensitive to cold, feels chilly.
- Dry warts with sharp, pointed, rough edges.

- Slight itching.

- History of cauterization of similar warts.

Table 1: Totality of symptoms and reportorial totality

\begin{tabular}{|c|c|}
\hline Arrogant and dominating in nature. & MIND - HAUGHTY \\
\hline Angers easily. & MIND - ANGER - trifles; at \\
\hline Suddenly forgets what he was thinking of. & MIND - THOUGHTS- vanishing of \\
\hline Desire for spicy, fried food. & GENERALS - FOOD and DRINKS - spices - desire \\
\hline Sleepy in morning. & SLEEP - SLEEPINESS - morning \\
\hline Sensitive to cold, feels chilly. & GENERALS HEAT - lack of vital heat \\
\hline Dry warts with sharp, pointed , rough edges. & SKIN - WARTS - jagged \\
\hline Slight itching. & SKIN - WARTS - itching \\
\hline History of cauterization of similar warts. & SKIN - WARTS - suppressed \\
\hline
\end{tabular}

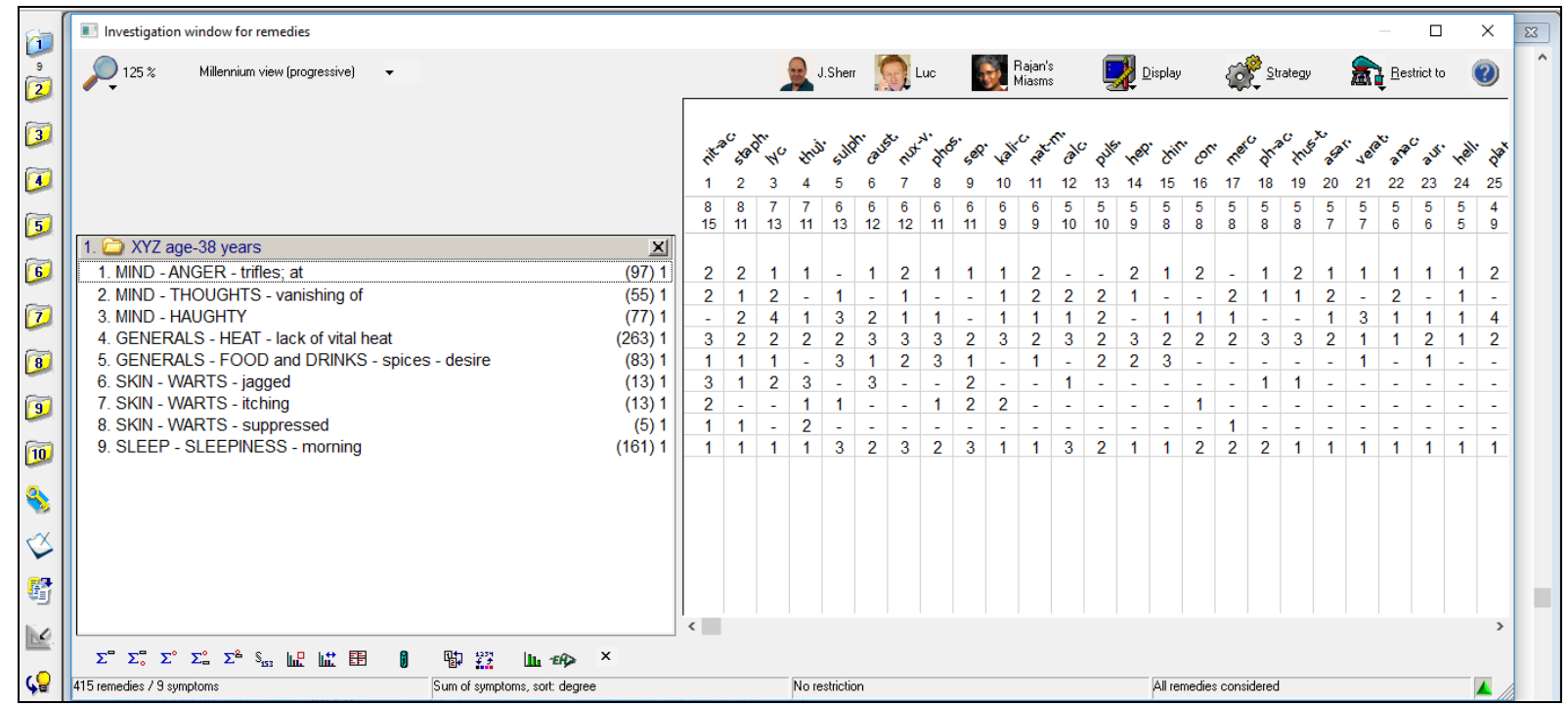

Fig 1: Repertorial sheet

\section{Repertorial result}

- Nitric acid - $15 / 8$

- Staphysagria - $11 / 8$

- Lycopodium - 13/7

- Thuja-11/7

- Sulphur - 13/6

\section{Prescription}

$\mathrm{Rx}$

Nitric acid 0/1 OD

Sac lac BD for 15 days

Table 2: Follow up

\begin{tabular}{|c|c|c|}
\hline Date & Symptoms & Prescription \\
\hline $16 / 10 / 2019$ & No change in symptoms. General betterment of the patient. & $\begin{array}{c}\text { Nit. Ac. 0/1 OD } \\
\text { S/L BD for 15 days }\end{array}$ \\
\hline $13 / 11 / 2019$ & General condition is better with marked improvement in itching. & $\begin{array}{c}\text { Nit. Ac. 0/2 OD } \\
\text { S/L BD for 1 month }\end{array}$ \\
\hline $10 / 12 / 2019$ & $\begin{array}{c}\text { Warts became more dry in appearance. No itching . Overall } \\
\text { patient is feeling better. Sour eructations reduced } . ~\end{array}$ & $\begin{array}{c}\text { Nit. Ac. 0/3 OD } \\
\text { S/L BD for 1 month }\end{array}$ \\
\hline $3 / 01 / 2020$ & Warts shade off while washing face. & $\begin{array}{c}\text { Nit. Ac. 0/4 OD for 15 days } \\
\text { S/L BD for next 15 days }\end{array}$ \\
\hline
\end{tabular}

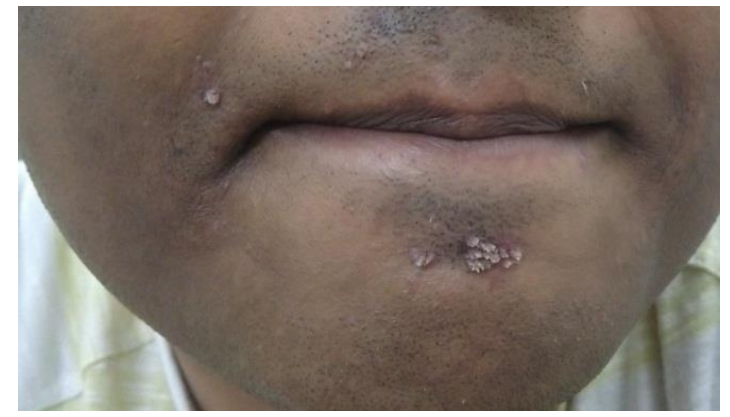

Fig 2: 2/10/2019 Before treatment

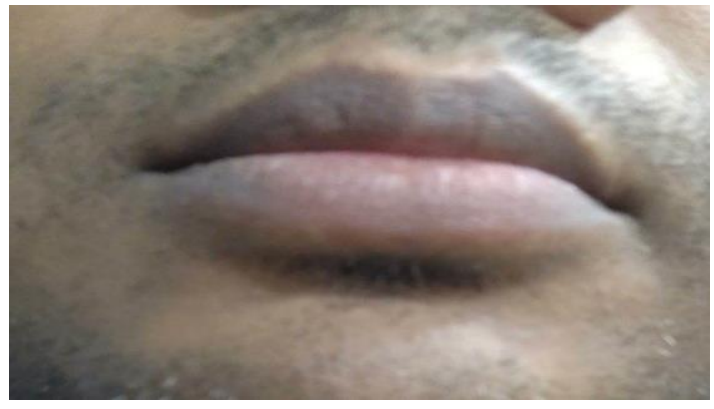

Fig 3: 03/01/2020 After treatment 


\section{Discussion and Conclusion}

In homoeopathy, prescription is based on either individual reportorial result or on the basis of therapeutic use of particular medicine and this above mentioned case was prescribed on the basis of reportorial result as the nitric acid medicine showed maximum marks in reportorial index by covering marked and peculiar symptom of the patient. In reportorial sheet maximum marks were gained by Nitric Acid and Staphysagria and nitric acid was prescribed. And potency selection was done on the basis of patient susceptibility and as mentioned in organon of medicine $5^{\text {th }}$ $\& 6^{\text {th }}$ edition under aph.270 f.n " In very rare cases, notwithstanding almost full recovery of health and with good vital strength, an old annoying local trouble continuing undisturbed it is wholly permitted and even indispensably necessary, to administer in increasing doses the homoeopathic remedy that has proved itself efficacious but potentised to a very high degree by means of many succession by hand such a local disease will offer disappear in a wonderful way ${ }^{[2]}$.

\section{Reference}

1. Hahnemann S, Boericke W, Dudgeon R. Organon of medicine. New Delhi: B. Jain Publishers 2011.

2. Khanna N. Dermatology and sexually transmitted diseases. 6th ed. New Delhi: Modern Publishers 2019. 